\title{
Comparison of wavefront aberrations under cycloplegic, scotopic and photopic conditions using WaveScan
}

\author{
Comparação de aberrações de frente de onda sob cicloplegia, condições escotópica e \\ fotópica usando WaveScan
}

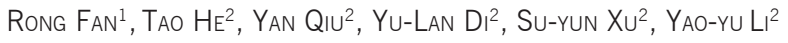

\begin{abstract}
Purpose: To evaluate the differences of wavefront aberrations under cycloplegic, scotopic and photopic conditions.

Methods: A total of 174 eyes of 105 patients were measured using the wavefront sensor (WaveScan ${ }^{\circledR}$ 3.62) under different pupil conditions: cycloplegic $8.58 \pm 0.54 \mathrm{~mm}$ $(6.4 \mathrm{~mm}-9.5 \mathrm{~mm})$, scotopic $7.53 \pm 0.69 \mathrm{~mm}(5.7 \mathrm{~mm}-9.1 \mathrm{~mm})$ and photopic $6.08 \pm$ $1.14 \mathrm{~mm}(4.1 \mathrm{~mm}-8.8 \mathrm{~mm})$. The pupil diameter, standard Zernike coefficients, root mean square of higher-order aberrations and dominant aberrations were compared between cycloplegic and scotopic conditions, and between scotopic and photopic conditions.

Results: The pupil diameter was $7.53 \pm 0.69 \mathrm{~mm}$ under the scotopic condition, which reached the requirement of about $6.5 \mathrm{~mm}$ optical zone design in the wavefrontguided surgery and prevented measurement error due to the pupil centroid shift caused by mydriatics. Pharmacological pupil dilation induced increase of standard Zernike coefficients $Z_{-}^{-3}, Z^{0}$ and $Z_{-5}^{-5}$. The higher-order aberrations, third-order aberration, fourth-order aberration, fifth-order aberration, sixth-order aberration, and spherical aberration increased statistically significantly, compared to the scotopic condition $(P<0.010)$. When the scotopic condition shifted to the photopic condition, the standard Zernike coefficients $Z_{4}^{0}, Z_{4}^{2}, Z_{6}^{-4}, Z_{6}^{-2}, Z_{6}^{2}$ decreased and all the higherorder aberrations decreased statistically significantly $(P<0.010)$, demonstrating that accommodative miosis can significantly improve vision under the photopic condition. Under the three conditions, the vertical coma aberration appears the most frequently within the dominant aberrations without significant effect by pupil size variance, and the proportion of spherical aberrations decreased with the decrease of the pupil size. Conclusions: The wavefront aberrations are significantly different under cycloplegic, scotopic and photopic conditions. Using the wavefront sensor (VISX WaveScan) to measure scotopic wavefront aberrations is feasible for the wavefront-guided refractive surgery.
\end{abstract}

Keywords: Accommodation, ocular/physiology; Mydriatics/administration \& dosage; Cornea/physiopathology; Diagnostic techniques, ophthalmological; Refractive errors; Corneal wavefront aberration; Refraction ocular; Pupil/physiology

\begin{abstract}
RESUMO
Objetivo: Avaliar as diferenças de aberrações de frente de onda, em diferentes condições pupilares: sob cicloplegia, escotópica e fotópica.

Métodos: Um total de 174 olhos de 105 pacientes foram avaliados utilizando o sensor de frente de onda (WaveScan ${ }^{\circledR}$ 3.62) em diferentes condições pupilares: sob cicloplegia $8,58 \pm 0,54 \mathrm{~mm}(6.4 \mathrm{~mm}-9.5 \mathrm{~mm})$, escotópica 7,53 $\pm 0,69 \mathrm{~mm}(5,7 \mathrm{~mm}-9,1 \mathrm{~mm})$ e fotópica 6,08 $\pm 1,14 \mathrm{~mm}(4,1 \mathrm{~mm}-8,8 \mathrm{~mm})$. Diâmetro da pupila, coeficientes de Zernike, RMS ("Root Mean Square") das aberrações de alta ordem e as aberrações dominantes foram comparados entre as condições sob cicloplegia e escotópica, e entre as condições escotópica e fotópica.
\end{abstract}

Resultados: O diâmetro da pupila foi 7,53 $\pm 0.69 \mathrm{~mm}$ sob a condição escotópica e atingiu a exigência de cerca de $6,5 \mathrm{~mm}$ de zona óptica na cirurgia baseada em análise de frentes de ondas, evitando erros de medição consequentes à mudança de centroide pupilarprovocada por midriáticos. A dilatação farmacológica da pupila induziu aumento dos coeficientes de Zernike $Z^{-3}, Z^{0}$ e $Z_{5}^{-5}$. As aberrações de mais alta ordem (terceira, quarta, quinta e sexta ordem) e a aberração esférica aumentaram de forma estatisticamente significativa, em comparação com a condição escotópica $(P<0,010)$. Quando a condição escotópica se mudou para a condição fotópica, os coeficientes de Zernike $Z_{4}^{0}, Z_{4}^{2}, Z_{6}^{-4}, Z_{6}^{-2}, Z_{6}^{2}$ e todas as aberrações de alta ordem diminuíram de forma estatisticamente significativa $(P<0,010)$, demonstrando que a miose acomodativa pode significativamente melhorar a visão sob a condição fotópica. Sob as três condições, a aberração coma vertical apareceu mais frequentemente dentro das aberrações dominantes, sem influência significativa da variação do tamanho da pupila, e a proporção de aberração esférica diminuiu com a diminuição do tamanho da pupila.

Conclusões: As aberrações de frente de onda são significativamente diferentes sob cicloplegia, condições escotópica e fotópica. O uso do sensor de frentes de onda (VISX WaveScan) para medir as aberrações de frente de onda escotópicas é uma opção viável para a cirurgia refrativa baseada em análise de frentes de onda.

Descritores: Acomodação ocular/fisiologia; Midriáticos/administração \& dosagem; Córnea/fisiopatologia; Técnicas de diagnóstico oftalmológico; Erros de refração; Aberrações de frente de onda da córnea; Refração ocular; Pupila/fisiologia

\section{INTRODUCTION}

Refractive surgery aims to ultimately regain favorable vision quality in myopia patients. The vision quality including the eye refraction medium, the optic nerve, and mental factors especially relates to the measurement of aberrations. The wavefront-guided refractive surgery is an effective method to achieve the aim, accounting for $67 \%$ to $91 \%$ of all refractive surgeries from 2003 to $2009^{(1,2)}$. A suitable customized wavefront correction might be one that minimizes aber- rations with an eye's natural pupil and its natural accommodative posture when viewing a distant object ${ }^{(3)}$. Using the self adapting optical system, the optic nerve was found to change in lower-order aberrations and higher-order aberrations ${ }^{(4)}$. When the refractive surgery or the contact lens changed the original aberration model, the visual cortex compensation recovered the original aberrations model, completely changing the time for aberrations and determining interests for patients. Thus in the refractive surgery, under-correction and over-correction of aberrations, or change of previous aberrations
Submitted for publication: November 27, 2011

Accepted for publication: February 3, 2012

Study was carried out at Department of Ophthalmology, General Hospital of Beijing, China.

Department of Ophthalmology, China Meitan General Hospital.

Department of Ophthalmology, General Hospital of Beijing.
Funding: No specific financial support was available for this study.

Disclosure of potential conflicts of interest: R.Fan, None; T.He, None; Y.Qiu, None; Y-L.Di, None; S.Xu, None, Y.Li, None.

Correspondence address: Yao-yu Li, Department of Ophthalmology, General Hospital of Beijing Command Area of PLA - Beijing 100.700, China - E-mail: leedoctor00@163.com 
lead to difficulty in postoperative aberration adaption, and possibly even vision complaints in some patients. So, it is very important to measure preoperative aberration in a feasible condition.

Currently, in different wavefront analysis systems and different Zernike polynomials ${ }^{(2,5-8)}$, there are two different measurements: with pupil dilation ${ }^{(3,7,9-12)}$ or without pupil dilation ${ }^{(2,12-15)}$, and there are also differences in patients'age, refraction conditions, sampling and statistical analysis, so no gold standard exists for wavefront devices ${ }^{(5,6)}$. There are two kinds of high order aberration detection: under cycloplegic conditions with pharmacological pupil dilation and under scotopic conditions with natural pupil dilation in a darkroom. Some studies show that pharmacological pupil dilation leads to uneven mydriasis, pupil centroid shift and eccentricity, causing change of different degrees to the higher-order aberrations $s^{(9,16-18)}$. Further studies are still required to investigate whether the difference in aberrations under cycloplegic and scotopic conditions exists and whether the aberrations under scotopic conditions match the natural condition of the eye. VISX S4 system (VISX USA, Inc., SantA Clara, CA) can measure aberrations over a 6-mm pupil diameter. We used the wavefront sensor (VISX WaveScan 3.62) to measure scotopic wavefront aberrations in young patients and compared them with data under cycloplegic and photopic conditions. This study evaluated the applicability of scotopic wavefront aberrations and intended to find out a feasible examining condition to get the whole information of high order aberrations accurately before surgery, so doctors can design an optimal ablation protocol in the wavefront-guided refractive surgery.

\section{METHODS}

\section{SubJects}

The subjects were enrolled from patients with myopia and myopic astigmatism who were candidates for wavefront-guided LASIK in the Excimer Laser Center, Military General Hospital of Beijing People's Liberation Army (Beijing, China) from January $10^{\text {th }}, 2010$ to March $10^{\text {th }}$, 2010. After approval from the Institutional Review Board for Human Research at the Military General Hospital of Beijing People's Liberation Army, all subjects signed an appropriate informed consent. Patients with a series of examination, including optometry, retinophotoscopy, corneal topography, corneal thickness, and intraocular pressure were enrolled. Inclusion criteria: All subjects were required to have stable refraction for at least to 2 years, discontinuation of contact lens use for at least 2 weeks and with best corrected visual acuity $\geq 20 / 20$. Exclusion criteria: Patients with a history of eye surgery, trauma, ocular surface diseases or intraocular diseases were excluded. Initially, a total of 125 patients (224 eyes) were included. Of them, 32 eyes were excluded because the pupil diameter did not meet the requirements for quantification under cycloplegic and photopic conditions and 18 excluded due to discontinuation of study. Ultimately, 174 (left, 85; right, 89) eyes from 105 patients (male, 48; female, 57) were enrolled.

\section{INSTRUMENTS}

The wavefront sensor (WaveScan 3.62) was purchased from AMO (Santa Clara, California, US). This instrument uses the Hartmann-Shack system of aberrometry for scotopic examination. WaveScan expresses results as Zernike polynomial coefficients up to and including the sixth order. The observation target is a very narrow spot red light source (0.02 Lux). The tunnel vision approach was considered for measurement, and the eye accommodation was relaxed with an automatic precompensation of $+8.00 \mathrm{D}$ during examination ${ }^{(19)}$. The system was adjusted every day when it was started. The examination procedure and data inclusion criteria for the three conditions were identical. Data inclusion criteria were as follows: the stability of four images with lower-order data and higher-order data were candidates. The images coincided with the pupil center, the corneal apex and iris center, clear iris, complete and clear Hartmann-Shack dot arrays were chosen. The pupil diameter was recorded under cycloplegic, scotopic and photopic conditions and the higher-order aberrations were extracted for quantification when the pupil diameter was $6 \mathrm{~mm}$.

\section{Methods}

The eyes were measured by the same wavefront sensor in terms of the wavefront aberrations (lower-order aberrations and higherorder aberrations) and the pupil diameter. Eye drops were stopped during measurements. In this study, the brightness of the environment light was $<1$ Lux for pharmacological and scotopic pupil dilations. According to the International Commission on Illumination, the lighting systems in the night including the roadway lighting and vehicle lighting have a higher brightness ( $\geq 1-2$ Lux). In the present study, illumination was lower than actual illumination at night, so it can simulate the night environment. Rapid mydriatics was a complex formula of tropicamide (Mydrin, $10 \mathrm{ml}$, containing tropicamide $50 \mathrm{mg}$ plus phenylephrine hydrochloride $50 \mathrm{mg}$ ) (Santen Pharmaceutical Co., Shiga, Japan). Dates were obtained under three conditions. 1) For wavefront aberrations under the photopic condition, natural pupils were measured under the natural light in room with brightness of 280 Lux (modelBM-7A; TOPCON, Japan 2) For wavefront aberrations under the scotopic condition, natural pupils were measured after the patients adapted to the dark room for $10 \mathrm{~min}$. 3) For wavefront aberrations under the cycloplegic condition, one drop of composite tropicamide was dropped in the examined eye and another drop was dropped after $10 \mathrm{~min}$ if necessary. In order to prevent increased lenticular accommodation during consecutive measurements, an interval of 20 min was required for examination between the photopic and scotopic conditions. The measurements were conducted within $2 \mathrm{~d}$.

\section{Statistical analysis}

SPSS (version 13.0) (SPSS Inc, Chicago, IL, USA) was used. The pupil diameter, standard Zernike coefficients, root mean square (RMS) of higher-order aberrations and dominant aberrations were compared between cycloplegic and scotopic conditions, and between scotopic and photopic conditions. For measurement differences with normal distribution, paired t-test was used for comparison; for measurement differences with abnormal distribution, Wilcoxon signed ranks test was used for comparison. A statistically significant difference was considered if $P$ was $<0.010$.

\section{RESULTS}

Patients' age ranged from 18 to 30 years, with a mean age of 22 years. They had spherical power of $-5.53 \pm 2.00 \mathrm{D}(-0.14 \mathrm{D}-10.56 \mathrm{D})$, and cylindrical power of $-0.95 \pm 0.77 \mathrm{D}(-0.40 \mathrm{D}-3.68 \mathrm{D})$. The pupil diameter was $8.58 \pm 0.54 \mathrm{~mm}(6.4 \mathrm{~mm}-9.5 \mathrm{~mm})$ under the cycloplegic condition, $7.53 \pm 0.69 \mathrm{~mm}(5.7 \mathrm{~mm}-9.1 \mathrm{~mm})$ under the scotopic condition, and $6.08 \pm 1.14 \mathrm{~mm}(4.1 \mathrm{~mm}-8.8 \mathrm{~mm})$ under the photopic condition. A statistically significant difference was noted in the pupil diameter between the cycloplegic and the scotopic condition $(Z=-11.312, P=0.000)$ and between the photopic and the scotopic condition $(t=24.403, P=0.000)$.

\section{HighER-ORDER ABERRATIONS \\ Cycloplegic and scotopic conditions}

Standard Zernike coefficients: $Z_{3}^{-3}(P=0.000), Z_{4}{ }^{0}(P=0.000)$ and $Z_{5}^{-5}(P=0.006)$ increased statistically significantly under the cycloplegic condition (Table 1 and Figure 1).

Regarding Zernike coefficients of higher-order aberrations (Root mean square), there were significant differences in the total higher-order aberration $(Z=-5.215, P=0.000)$, third-order aberration $(Z=-11.341$, $P=0.000)$, fourth-order aberration ( $t=25.422, P=0.000)$, fifth-order aberration $(Z=-11.440, P=0.000)$, sixth-order aberration $(Z=-11.440$, $P=0.000)$, and spherical aberration $\left(Z_{4}^{0}\right.$ and $\left.Z_{6}{ }^{0}\right)(t=3.694, P=0.000)$. 
Table 1. Normalized standard Zernike coefficients $(\mu \mathrm{m})$ under cycloplegic and scotopic pupil conditions

\begin{tabular}{|c|c|c|c|c|c|}
\hline & & Cycloplegic & Scotopic & & \\
\hline J & Term & Mean \pm SD & Mean \pm SD & & $P \circledast$ \\
\hline 6 & $\mathbf{Z}_{3}^{-3}\left(3^{\text {rd }}\right)$ & $-0.061 \pm 0.167$ & $-0.026 \pm 0.161$ & $Z=-4.222$ & $0.000 *$ \\
\hline 7 & $Z_{3}^{-1}$ & $0.052 \pm 0.225$ & $0.037 \pm 0.213$ & $t=1.813$ & 0.072 \\
\hline 8 & $Z_{3}{ }^{1}$ & $0.010 \pm 0.129$ & $0.008 \pm 0.125$ & $t=0.380$ & 0.705 \\
\hline 9 & $\mathrm{Z}_{3}^{3}$ & $0.001 \pm 0.136$ & $-0.002 \pm 0.128$ & $t=0.640$ & 0.523 \\
\hline 10 & $Z_{4}^{-4}\left(4^{\text {th }}\right)$ & $0.004 \pm 0.071$ & $0.004 \pm 0.057$ & $Z=-0.179$ & 0.858 \\
\hline 11 & $Z_{4}^{-2}$ & $-0.010 \pm 0.061$ & $-0.006 \pm 0.050$ & $t=-1.277$ & 0.203 \\
\hline 12 & $Z_{4}{ }^{0}$ & $0.111 \pm 0.146$ & $0.066 \pm 0.149$ & $t=8.092$ & $0.000 *$ \\
\hline 13 & $Z_{4}^{2}$ & $0.015 \pm 0.087$ & $0.014 \pm 0.077$ & $t=0.327$ & 0.744 \\
\hline 14 & $Z_{4}^{4}$ & $0.018 \pm 0.077$ & $0.010 \pm 0.069$ & $t=1.845$ & 0.067 \\
\hline 15 & $\mathbf{Z}_{5}^{-5}\left(5^{\text {th }}\right)$ & $-0.016 \pm 0.050$ & $-0.006 \pm 0.038$ & $Z=-2.763$ & $0.006 *$ \\
\hline 16 & $Z_{5}^{-3}$ & $-0.004 \pm 0.046$ & $-0.002 \pm 0.041$ & $Z=-0.436$ & 0.663 \\
\hline 17 & $Z_{5}^{-1}$ & $0.004 \pm 0.052$ & $0.000 \pm 0.044$ & $t=0.992$ & 0.323 \\
\hline 18 & $Z_{5}^{1}$ & $0.000 \pm 0.030$ & $0.001 \pm 0.029$ & $t=-0.650$ & 0.517 \\
\hline 19 & $Z_{5}^{3}$ & $0.000 \pm 0.035$ & $0.001 \pm 0.025$ & $Z=-0.824$ & 0.410 \\
\hline 20 & $Z_{5}^{5}$ & $0.002 \pm 0.039$ & $0.002 \pm 0.030$ & $Z=-0.629$ & 0.529 \\
\hline 21 & $Z_{6}^{-6}\left(6^{\text {th }}\right)$ & $0.000 \pm 0.032$ & $-0.003 \pm 0.025$ & $t=1.934$ & 0.055 \\
\hline 22 & $Z_{6}^{-4}$ & $0.000 \pm 0.026$ & $0.000 \pm 0.021$ & $Z=-0.135$ & 0.893 \\
\hline 23 & $Z_{6}^{-2}$ & $0.001 \pm 0.022$ & $0.000 \pm 0.016$ & $Z=-0.933$ & 0.351 \\
\hline 24 & $Z_{6}^{0}$ & $-0.004 \pm 0.042$ & $-0.004 \pm 0.041$ & $t=-0.146$ & 0.884 \\
\hline 25 & $Z_{6}^{2}$ & $0.005 \pm 0.034$ & $0.011 \pm 0.027$ & $Z=-1.704$ & 0.088 \\
\hline 26 & $Z_{6}^{4}$ & $0.001 \pm 0.029$ & $-0.001 \pm 0.026$ & $t=1.297$ & 0.196 \\
\hline 27 & $Z_{6}^{6}$ & $0.006 \pm 0.036$ & $0.009 \pm 0.030$ & $Z=-1.293$ & 0.196 \\
\hline
\end{tabular}

$※=$ the paired-samples $t$ test or Wilcoxon matched-pairs singed-rank test

$*$ statistically significant between two conditions $(P<0.01)$

$\mathrm{P}=$ comparison of cycloplegic eyes and scotopic eyes

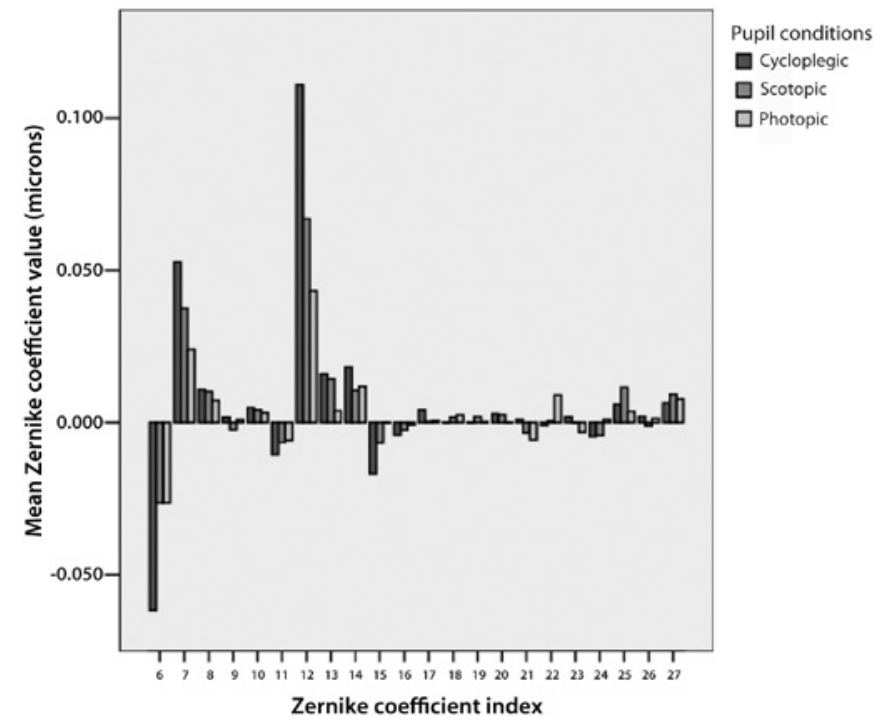

Figure 1. Normalized standard Zernike coefficient values under three pupil conditions $\left(3^{\text {rd }}-6^{\text {th }}\right)$

No statistically significant differences were noted in the coma aberration (including $Z_{3}{ }^{-1}, Z_{3}{ }^{1}, Z_{5}{ }^{-1}$, and $\left.Z_{5}{ }^{1}\right)(t=2.593, P=0.010)$ between two groups (Table 3).

\section{Scotopic and photopic conditions}

Standard Zernike coefficients: $Z_{4}^{0}(P=0.000), Z_{4}{ }^{2}(P=0.009), Z_{6}^{-4}$ $(P=0.000), Z_{6}^{-2}(P=0.003)$, and $Z_{6}^{2}(P=0.000)$ decreased statistically significantly under the photopic condition (Table 2 and Figure 1).

Regarding Zernike coefficients of higher-order aberrations (Root mean square), there were statistically significant differences in the total higher-order aberration ( $t=11.339, P=0.000)$, third-order aberration ( $t=9.782, P=0.000)$, fourth-order aberration ( $t=11.576$, $P=0.000)$, fifth-order aberration $(Z=-6.253, P=0.000)$, sixth-order aberration $(Z=-5.785, P=0.000)$, coma aberration (including $Z_{3}{ }^{-1}, Z_{3}{ }^{1}$, $Z_{5}^{-1}$, and $\left.Z_{5}{ }^{1}\right)(Z=-8.490, P=0.000)$, and spherical aberration $\left(Z_{4}{ }^{0}\right.$ and $\left.Z_{6}{ }^{\circ}\right)(Z=-8.503, P=0.000)$ (Table 3).

\section{Dominant aberRations}

There was a statistically significant difference in dominant aberrations between the cycloplegic and the scotopic condition ( $t=5.351$, $P=0.000$ ), and between the scotopic and the photopic condition $(Z=-8.806, P=0.000)$. RMS of dominant aberrations gradually decreased from cycloplegic, scotopic, to photopic conditions. The proportions of coma aberrations and trefoil aberrations were consistent with the three conditions. The proportion of vertical coma aberrations accounted for the most under the three conditions. The proportion of spherical aberrations decreased proportionally when the pupil size decreased (26\% in the cycloplegic condition, $21 \%$ in the scotopic condition, and $16 \%$ in the photopic condition) (Figure 2). 
Table 2. Normalized standard Zernike coefficients $(\mu \mathrm{m})$ under scotopic and photopic pupil conditions

\begin{tabular}{|c|c|c|c|c|c|}
\hline & & Scotopic & Photopic & & \\
\hline J & Term & Mean \pm SD & Mean \pm SD & & $P \circledast$ \\
\hline 6 & $\mathbf{Z}_{3}^{-3}\left(3^{\text {rd }}\right)$ & $-0.026 \pm 0.161$ & $-0.027 \pm 0.131$ & $Z=-0.307$ & 0.759 \\
\hline 7 & $Z_{3}^{-1}$ & $0.037 \pm 0.213$ & $0.024 \pm 0.159$ & $t=1.609$ & 0.109 \\
\hline 8 & $Z_{3}{ }^{1}$ & $0.008 \pm 0.125$ & $0.007 \pm 0.084$ & $Z=-0.835$ & 0.404 \\
\hline 9 & $\mathrm{Z}_{3}{ }^{3}$ & $-0.002 \pm 0.128$ & $0.000 \pm 0.101$ & $Z=-0.932$ & 0.351 \\
\hline 10 & $Z_{4}^{-4}\left(4^{\text {th }}\right)$ & $0.004 \pm 0.057$ & $0.003 \pm 0.045$ & $t=0.287$ & 0.775 \\
\hline 11 & $\mathrm{Z}_{4}^{-2}$ & $-0.006 \pm 0.050$ & $-0.005 \pm 0.034$ & $t=-0.182$ & 0.855 \\
\hline 12 & $\mathbf{Z}_{4}{ }^{0}$ & $0.066 \pm 0.149$ & $0.043 \pm 0.106$ & $t=3.624$ & $0.000 *$ \\
\hline 13 & $\mathbf{Z}_{4}^{2}$ & $0.014 \pm 0.077$ & $0.003 \pm 0.068$ & $t=2.637$ & $0.009 *$ \\
\hline 14 & $Z_{4}^{4}$ & $0.010 \pm 0.069$ & $0.011 \pm 0.058$ & $t=-0.316$ & 0.752 \\
\hline 15 & $Z_{5}^{-5}\left(5^{\text {th }}\right)$ & $-0.006 \pm 0.038$ & $-0.000 \pm 0.031$ & $t=-2.322$ & 0.021 \\
\hline 16 & $Z_{5}^{-3}$ & $-0.002 \pm 0.041$ & $-0.000 \pm 0.035$ & $Z=-0.789$ & 0.430 \\
\hline 17 & $Z_{5}^{-1}$ & $0.000 \pm 0.044$ & $0.000 \pm 0.035$ & $Z=-0.887$ & 0.375 \\
\hline 18 & $Z_{5}{ }^{1}$ & $0.001 \pm 0.029$ & $0.002 \pm 0.026$ & $t=-0.351$ & 0.726 \\
\hline 19 & $Z_{5}^{3}$ & $0.001 \pm 0.025$ & $0.000 \pm 0.022$ & $Z=-1.552$ & 0.121 \\
\hline 20 & $Z_{5}^{5}$ & $0.002 \pm 0.030$ & $0.000 \pm 0.028$ & $t=1.093$ & 0.276 \\
\hline 21 & $Z_{6}^{-6}\left(6^{\text {th }}\right)$ & $-0.003 \pm 0.025$ & $-0.005 \pm 0.023$ & $t=1.267$ & 0.207 \\
\hline 22 & $Z_{6}^{-4}$ & $0.000 \pm 0.021$ & $0.008 \pm 0.021$ & $Z=-4.118$ & $0.000 *$ \\
\hline 23 & $Z_{6}^{-2}$ & $0.000 \pm 0.016$ & $-0.003 \pm 0.016$ & $Z=-2.946$ & $0.003^{*}$ \\
\hline 24 & $Z_{6}^{0}$ & $-0.004 \pm 0.041$ & $0.000 \pm 0.032$ & $Z=-1.990$ & 0.047 \\
\hline 25 & $Z_{6}^{2}$ & $0.011 \pm 0.027$ & $0.003 \pm 0.021$ & $t=3.644$ & $0.000 *$ \\
\hline 26 & $Z_{6}^{4}$ & $-0.001 \pm 0.026$ & $0.001 \pm 0.021$ & $Z=-1.493$ & 0.135 \\
\hline 27 & $z^{6}$ & $0.009 \pm 0.030$ & $0.007 \pm 0.026$ & $t=0.665$ & 0.507 \\
\hline
\end{tabular}

$※=$ the paired-samples $t$ test or Wilcoxon matched-pairs singed-rank test

* = statistically significant between two conditions $(P<0.01)$

$P=$ comparison of scotopic eyes and photopic eyes

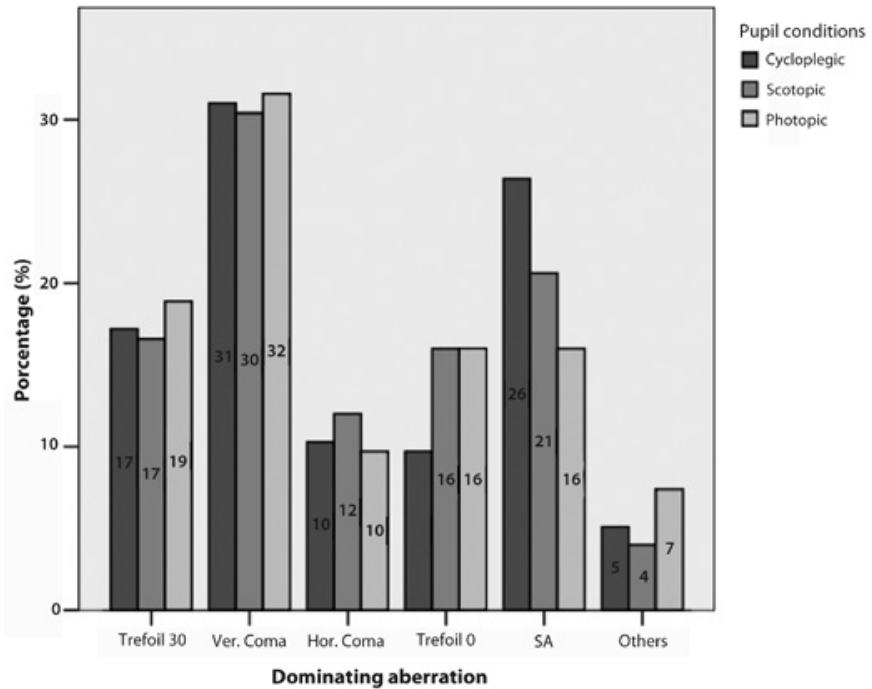

Figure 2. The Dominating aberration attribution under the three pupil conditions.

\section{DISCUSSION}

Wavefront-guided customized ablation is a new technique in refractive surgery performed with the goal to obtain an aberration-free optical system for the eye ${ }^{(20)}$. The surgeon designs the ablation protocol according to the diopter, corneal thickness, higher-order aberration and night pupil size.

\section{PuPIL SIZE}

The pupil diameter was $7.53 \pm 0.69 \mathrm{~mm}$ under the scotopic condition, indicating that the wavefront aberration measurement under the scotopic condition can meet the requirement of the optical zone of $6.5 \mathrm{~mm}$ for the wavefront-guided surgery. The pupil diameter changes drastically in different conditions $(P<0.010)$.

\section{Pharmacological pupil dilation and scotopic CONDITION}

Totally 15 men and 4 women, whose average age is 29 (range 19 to 56 years old), were examined using VISX WaveScan ${ }^{(7)}$. They found that the repeatability coefficient of higher-order aberrations was only $0.08 \mu \mathrm{m}$ with limited deviation. In their study, after use of $1 \%$ Tropicamide Ophthalmic Solution USP (Bausch \& Lomb, Rochester, New York), RMS of higher-order aberrations was $0.47 \pm 01.7 \mu \mathrm{m}$; RMS of coma aberrations, $0.26 \pm 0.15 \mu \mathrm{m}$; and RMS of spherical aberrations, $0.12 \pm 0.21 \mu \mathrm{m}$. These findings were consistent with ours following pharmacological pupil dilation. In the current research, following pharmacological pupil dilation, the higher-order aberrations $Z_{3}^{-3}$ increased by $134 \%$, and $Z_{4}^{0}$ increased by $68 \%(P<0.010)$ (Figure 1$)$. All the higher-order aberrations increased statistically significantly $(P<0.010)$ excepting for coma aberrations $(P=0.010)$. We found that the difference of higher-order aberrations was lower than $0.1 \mu \mathrm{m}$ before and after pharmacological pupil dilation, though still with statistically significant difference. This can be explained in the following paragraph. 
Table 3. Wavefront aberrations under three pupil conditions (RMS)

\begin{tabular}{|c|c|c|c|c|c|}
\hline \multirow[b]{2}{*}{ Parameters } & \multirow{2}{*}{$\frac{\text { Cycloplegic }}{\text { Mean } \pm \text { SD }}$} & \multirow[b]{2}{*}{$※ P_{1}$} & \multirow{2}{*}{$\begin{array}{c}\text { Scotopic } \\
\text { Mean } \pm \text { SD }\end{array}$} & \multirow{2}{*}{$\begin{array}{c}\text { Photopic } \\
\text { Mean } \pm \text { SD }\end{array}$} & \multirow[b]{2}{*}{$※ P_{2}$} \\
\hline & & & & & \\
\hline HOA RMS & $0.426 \pm 0.120$ & $0.000 *$ & $0.398 \pm 0.124$ & $0.278 \pm 0.145$ & $0.000 *$ \\
\hline $3^{\text {rd }}$ RMS & $0.475 \pm 0.208$ & $0.000 *$ & $0.296 \pm 0.132$ & $0.212 \pm 0.127$ & $0.000 *$ \\
\hline $4^{\text {th }}$ RMS & $0.318 \pm 0.089$ & $0.002 *$ & $0.192 \pm 0.081$ & $0.131 \pm 0.086$ & $0.000 *$ \\
\hline $5^{\text {th }}$ RMS & $0.140 \pm 0.054$ & $0.000 *$ & $0.080 \pm 0.034$ & $0.062 \pm 0.039$ & $0.000 *$ \\
\hline $6^{\text {th }} \mathrm{RMS}$ & $0.115 \pm 0.046$ & $0.000 *$ & $0.068 \pm 0.030$ & $0.054 \pm 0.032$ & $0.000 *$ \\
\hline Coma & $0.238 \pm 0.131$ & 0.010 & $0.220 \pm 0.129$ & $0.153 \pm 0.108$ & $0.000 *$ \\
\hline SA & $0.159 \pm 0.100$ & $0.000 *$ & $0.140 \pm 0.092$ & $0.091 \pm 0.076$ & $0.000 *$ \\
\hline Dominating aberration & $0.286 \pm 0.108$ & $0.000 *$ & $0.256 \pm 0.109$ & $0.179 \pm 0.109$ & $0.000 *$ \\
\hline \multicolumn{6}{|c|}{$\begin{array}{l}\text { ※= the paired-samples } t \text { test or Wilcoxon matched-pairs singed-rank test } \\
{ }^{*}=\text { statistically significant between two conditions }(P<0.01) \\
P_{1}=\text { comparison of cycloplegic eyes and scotopic eyes } \\
P_{2}=\text { comparison of scotopic eyes and photopic eyes } \\
H^{\prime O A}=\text { higher-order aberration, } 3^{\text {rd }} \text { order to } 6^{\text {th }} \text { order } \\
\text { Coma = square root of the sum of the squared coefficients of } Z_{3}^{-1}, Z_{3}{ }^{1}, Z_{5}^{-1} \text { and } Z_{5}{ }^{1} \\
S A=\text { square root of the sum of the squared coefficients of } Z_{4}^{0} \text { and } Z_{6}^{0} \\
\text { Dominating aberration= the absolute Zernike coefficient was the biggest value in }\end{array}$} \\
\hline
\end{tabular}

Firstly, the increase of the pupil diameter causes increase of higherorder aberrations. The NIDEK OPD-Scan was used for 102 eyes of 51 myopic patients ${ }^{(10)}$. When higher-order aberrations at the pupil size of $4 \mathrm{~mm}, 5 \mathrm{~mm}$, and $6 \mathrm{~mm}$ were compared following use of $1 \%$ tropicamide, all higher-order aberrations increased unevenly as the pupil diameter increased, and the spherical aberrations were larger than the coma aberrations. This implies that there is a difference in higher-order aberrations for different pupil diameters even in the one time detecting procedure. This means that the higher-order aberrations increase with the pupil diameter for the same lenticular accommodation.

Secondly, pharmacological pupil dilation can cause uneven mydriasis and pupil centroid shift, leading to differences in higher-order aberrations ${ }^{(3,16)}$. Higher-order aberrations obtained by WaveScan in natural and pharmacological pupil dilation conditions were compared, and the results showed that pupil centroid shift $\geq 0.2 \mathrm{~mm}$ existed in $45 \%$ patients following pharmacological pupil dilation, causing damage to postoperative vision ${ }^{(9)}$.

Thirdly, the aberrations can be compensated by lenticular accommodation under physiological conditions (21). Pharmacological pupil dilation reduces this compensation leading to increase of higher-order aberrations. Regarding the higher-order aberrations under scotopic condition using VISX WaveScan of patients before surgery, a group ${ }^{(13)}$ examined 532 eyes of 306 patients, whose average age is $41 \pm 10$ years (20 to 71 years), and another group ${ }^{(2)}$ examined 92 eyes of 51 patients, whose average age is 35 (23 to 58 years). The higher-order aberrations were extracted when the pupil diameter was $6 \mathrm{~mm}$. Our results of Zernike coefficients and RMS of higher-order aberrations, coma aberrations, and spherical aberrations were consistent with those reported. In the dark environment, the pupil is naturally dilated and with natural lenticular accommodation the aberrations compensation from the lens is maintained as well to prevent the measurement error due to pharmacological pupil dilation ${ }^{(22)}$. In this situation, higher-order aberrations were close to those got in the physiological status at night. Consequently, the measurement for natural eyes in the dark room is feasible for the refractive surgyery.

\section{COMPARISON OF THE SCOTOPIC CONDITION AND THE PHOTOPIC CONDITION}

When the scotopic condition was shifted to the photopic condition, the standard Zernike coefficients $Z_{4}^{0}, Z_{4}{ }^{2}, Z_{6}^{-4}, Z_{6}^{-2}$ and $Z_{6}^{2}$ decreased significantly $(P<0.010)$. All higher-order aberrations decreased statistically significantly $(P<0.010)$. Under both scotopic and photopic conditions, lenticular accommodation is maintained and this increases when the brightness changes. Changes to fourth-order and sixthorder aberrations after the accommodation were also reported ${ }^{(23-24)}$. Our research demonstrates that miotic accommodation apparently improves the vision quality. The WaveScan analyzes data reflected by the retina through the pupil using an objective technique, so the photo reception of photosensory cells determines the clear images ${ }^{(25)}$. When the scotopic condition shifts to the photopic condition, iridis sphincter is contracted to decrease the pupil diameter, thus increasing sensitization of objects projected to the retinal cells, and keeping images clear on the retina. This also explains why clear vision is obtained through pinhole imaging and why miotics are used in clinical practice for patients with poor night vision. In this study, higher-order aberrations and other aberrations decreased apparently under the photopic condition, showing that increased lenticular accommodation and pupil contraction together helps to improve vision quality under the photopic condition.

\section{Dominant ABERRATIONS}

Under different conditions, the most common dominant aberrations included coma aberrations, trefoil aberrations and spherical aberrations, which is consistent with previously reported data ${ }^{(26,27)}$. In this study, the vertical coma aberrations accounted for about $\geq 30 \%$, highest under all three conditions and no significant effect by pupil size variance, implying that the vertical coma aberrations appear the most frequent within the dominant aberrations. Additionally, the proportion of spherical aberrations decreases significantly when the pupil size decreases (Figure 2). The change of spherical aberrations and coma aberrations influence largely the third-order aberrations, and fourth-aberrations as well as the higher-order aberrations, as accepted by many researchers ${ }^{(3,14,28-29)}$. So, precise measurement of spherical aberration and coma before surgery plays an important role in vision recovery.

\section{CONCLUSION}

Different wavefront aberrations are closely correlated with the pupil size, so selection of appropriate wavefront measurement is essential for the wavefront-guided refractive surgery. The wavefront measurements under the scotopic condition with natural pupil by the WaveScan can meet the optical zone requirement of $6.5 \mathrm{~mm}$ for the wavefront-guided LASIK. 


\section{REFERENCES}

1. Duffey RJ, Leaming D. US trends in refractive surgery: 2004 ISRS/AAO Survey. J Refract Surg. 2005;21(6):742-8

2. Kim DS, Narvaez J, Krassin J, Bahjir K. Comparison of the VISX wavescan and NIDEK OPD-scan aberrometers. J Refract Surg. 2009;25(5):429-34.

3. Carkeet A, Velaedan S, Tan YK, Lee DY, Tan DT. Higher order ocular aberrations afte cycloplegic and non-cycloplegic pupil dilation. J Refract Surg. 2003;19(3):316-22.

4. Artal P, Chen L, Fernandez EJ, Singer B, Manzanera S, Williams DR. Neural compensation for the eye's optical aberrations. J Vis. 2004;4(4):281-7.

5. Rozema JJ, Van Dyck DE, Tassignon MJ. Clinical comparison of 6 aberrometers. Part 2: statistical comparison in a test group. J Cataract Refract Surg. 2006;32(1):33-44.

6. Wei RH, Lim L, Chan WK, Tan DT. Higher order ocular aberrations in eyes with myopia in a Chinese population. J Refract Surg. 2006;22(7):695-702.

7. Burakgazi AZ, Tinio B, Bababyan A, Niksarli KK, Asbell P. Higher order aberrations in normal eyes measured with three different aberrometers. J Refract Surg. 2006;22(9): 898-903.

8. Liang CL, Juo SH, Chang CJ.Comparison of higher-order wavefront aberrations with 3 aberrometers. J Cataract Refract Surg.2005;31(11):2153-6.

9. Tuan KA, Somani S, Chernyak DA. Changes in wavefront aberration with pharmaceutical dilating agents. J Refract Surg. 2005:21(5):S530-4

10. Wang Y, Zhao K, Jin Y, Niu Y, Zuo T. Changes of higher order aberration with various pupil sizes in the myopic eye. J Refract Surg. 2003;19(2 Suppl):S270-4.

11. Jankov MR 2nd, Iseli HP, Bueeler M, Schor P, Seiler T, Mrochen M. The effect of phenylephrine and cyclopentolate on objective wavefront measurements. J Refract Surg 2006:22(5):472-81.

12. Wang $L$, Koch DD. Ocular higher-order aberrations in individuals screened for refractive surgery. J Cataract Refract Surg. 2003;29(10):1896-903

13. Awwad ST, El-Kateb M, McCulley JP. Comparative higher-order aberration measurement of the LADARWave and Visx WaveScan aberrometers at varying pupil sizes and after pharmacologic dilation and cycloplegia. J Cataract Refract Surg. 2006;32(2): 203-14. Comment in: J Cataract Refract Surg. 2006;32(11):1898; author reply 1898.

14. Wang L, Santaella RM, Booth M, Koch DD. Higher-order aberrations from the internal optics of the eye. J Cataract Refract Surg. 2005;31(8):1512-9.

15. McAlinden C, Moore JE. Higher order aberrations using the NIDEK OPD-Scan and AMO WaveScan. J Refract Surg. 2010;26(8):605-8.
16. Walsh $\mathrm{G}$. The effect of mydriasis on the pupillary centration of the human eye. Oph thalmic Physiol Opt. 1988:8(2):178-82

17. Yang Y, Thompson K, Burns SA. Pupil location under mesopic, photopic, and pharmacologically dilated conditions. Invest Ophthalmol Vis Sci. 2002;43(7):2508-12.

18. Tabernero J, Atchison DA, Markwell EL. Aberrations and pupil location under corneal topography and Hartmann-Shack illumination conditions. Invest Ophthalmol Vis Sci. 2009;50(4):1964-70.

19. Wickremasinghe SS, Smith GT, Stevens JD. Comparison of dynamic digital pupillometry and static measurements of pupil size in determining scotopic pupil size before refractive surgery. J Cataract Refract Surg. 2005:31(6):1171-6. Comment in: J Cataract Refract Surg. 2006;32(5):702; author reply 702.

20. MacRae S, Schwiegerling J, Snyder RW. Customized and low spherical aberration corneal ablation design. J Refract Surg. 1999:15(2 Suppl):S246-8.

21. Artal P, Berrio E, Guirao A, Piers P. Contribution of the cornea and internal surfaces to the change of ocular aberrations with age. J Opt Soc Am A Opt Image Sci Vis. 2002; 19(1):137-43.

22. Subbaram MV, MacRae SM. Does dilated wavefront aberration measurement provide better postoperative outcome after custom LASIK? Ophthalmology. 2006:113(10): 1813-7.

23. Buehren T, Collins MJ. Accommodation stimulus-response function and retinal image quality. Vision Res. 2006:46(10):1633-45

24. López-Gil N, Fernández-Sánchez V, Legras R, Montés-Mico R, Lara F, Nguyen-Khoa JL. Accommodation-related changes in monochromatic aberrations of the human eye as a function of age. Invest Ophthalmol Vis Sci. 2008:49(4):1736-43.

25. Qu XM WL, Zhou XT, Dai JH. Analysis of the value of the aberrometer as a basic method for subjective refraction. Chin J Opt Ophthalmol. 2007:9:380-6.

26. Howland HC, Howland B. A subjective method for the measurement of monochromatic aberrations of the eye. J Opt Soc Am. 1977;67(11):1508-18.

27. Netto MV, Ambrosio R Jr, Shen TT, Wilson SE. Wavefront analysis in normal refractive surgery candidates. J Refract Surg. 2005;21(4):332-8.

28. Oshika T, Okamoto C, Samejima T, Tokunaga T, Miyata K. Contrast sensitivity function and ocular higher-order wavefront aberrations in normal human eyes. Ophthalmology. 2006;113(10):1807-12.

29. Kim JH, Lim T, Kim MJ, Tchah H. Changes of higher-order aberrations with the use of various mydriatics. Ophthalmic Physiol Opt. 2009;29(6):602-5.

\title{
$11^{\circ}$ Congresso da Sociedade de Oftalmologia do Triângulo Mineiro
}

\author{
25 a 27 de outubro de 2012 \\ CDL Convenções e Eventos - Uberlândia (MG)
}

Informações: 